\title{
METHOIN IN THE TREATMENT OF EPILEPSY
}

BY

D. P. JONES, M.D., M.R.C.P.

Medical Registrar, Maida Vale Hospital for Nervous Diseases; late Medical Registrar, Maudsley Hospital

During the past five years several new anti-epileptic drugs have become available for clinical use: of these troxidone ("tridione") is well known in the treatment of petit mal. This paper is a report on a trial of methoin (" mesontoin"; 3-methyl-5,5-phenylethyl hydantoin), a preparation mainly effective against other varieties of epilepsy. The drug is chemically allied to phenytoin, and is also related to the toxic drug phenylethylhydantoin (" nirvanol ") and to troxidone (Ruskin, 1948)-a fact of some significance when considering its toxic effects. It is dispensed as a pink tablet of $0.1 \mathrm{~g}$.

Clinical trials were first made in 1937 by Boller (1943), who regarded it as valuable but potentially toxic. Results were first published in America in 1945, since when numerous reports upon its use have been made, though no detailed study has appeared in the literature of this country.

Loscalzo (1945, 1946, 1947, 1948), using sodium diphenylhydantoinate ("dilantal") in a four-year study, reported a $60 \%$ reduction of fits in patients suffering from major and minor epilepsy. Toxic effects were few, and the absence of gum hypertrophy and ataxia (common toxic symptoms with phenytoin) was notable. Kozol (1946, 1947, 1950), using doses of up to $1.8 \mathrm{~g}$. a day, treated 200 patients for periods of up to four years, and found a $90 \%$ reduction in frequency of fits even though the majority of cases were resistant to phenytoin. Most of his cases suffered from major epilepsy, but the drug was also of use in psychomotor seizures, though not in petit mal. Methoin and phenytoin were sometimes given together, with apparently a synergistic effect; phenobarbitone was not used, as methoin alone exerted a well-marked soporific effect. Harris and Otto (1947) treated 20 cases of psychomotor epilepsy and found that 13 were rendered attack-free. Fetterman and Weil (1947), Fetterman et al. (1947), and Fetterman and Victoroff (1949), in a trial with 150 patients, considered methoin to be highly effective in major epilepsy, valuable in Jacksonian epilepsy, and of occasional use in psychomotor attacks. They stressed that good results werc achieved when other remedies had failed. In petit mal the drug was not of use. Aird (1948) reported a group of 75 patients resistant to other measures, and found almost complete control in more than half the cases of major, psychomotor, and Jacksonian epilepsy.

Although valuable, it soon became apparent that methoin was also sometimes toxic, and that its use called for the same careful supervision as with troxidone. Gibbs (1947) found that toxic reactions developed in $10 \%$ of patients, while of Lennox's (1946) cases $14 \%$ had a rash. Kozol (1947) reported a $6 \%$ incidence of morbilliform rashes during the first month of treatment, but thought that reactions were made less likely by the use of small initial doses. Loscalzo (1948) stated that a history of previous sensitization reactions was common in patients developing a rash, and stressed the need for a careful history in this respect.
Drowsiness was commonly reported as a side-effect of methoin, but gum hypertrophy and ataxia, which so often occur during phenytoin treatment, were rarely seen.

Minor blood changes were found in $18 \%$ of Fetterman and Victoroff's (1949) cases, and Lennox (1946) reported a relative lymphocytosis in $40 \%$ of his series. Other authors often commented on the occurrence of a relative lymphocytosis and also of eosinophilia, the latter particularly in the presence of dermatitis.

Serious reported toxic effects included aplastic anaemia and exfoliative dermatitis. In the American literature there are reports of six fatal cases of aplastic anaemia and of eight cases that recovered. The reactions occurred three to eighteen months after starting methoin therapy. Abbott and Schwab (1950), in reviewing the problem, thought that serious blood disorders were not of sudden onset as was held by some, but represented the sudden culmination of a progressive process. They thought it possible that patients developing a sensitization dermatitis were less likely to suffer a serious toxic effect subsequently.

Exfoliative dermatitis is reported in four cases, two being fatal (Ruskin, 1948 ; Kozol, 1950).

Hepatic disease was found in two fatal cases: one treated with methoin had a central lobular necrosis, and one developed a fatal hepato-renal syndrome following treatment with methoin, troxidone, and phenurone (Levy et al., 1950). Ruskin (1948) states that methoin and troxidone are both potentially toxic, and that both are related to the toxic substance phenylethylhydantoin; combined use of the drugs is therefore dangerous.

\section{Present Investigation}

Cases were selected for methoin treatment only after other remedies had been proved ineffective in full tolerated dosage. Patients suffering from petit mal were not given methoin, as published results were so uniformly discouraging. Altogether 41 patients were treated, but only 24 (13 female, 11 male) were considered suitable for assessment; the others either failed to take the drug regularly or omitted to keep adequate records of the numbers of their attacks. The average age was 30 , the youngest being 10 years old.

A detailed history was taken in order to determine the type of epilepsy, and careful reference was made to previous drug sensitivity or other form of allergy. Treatment was usually begun with $0.1 \mathrm{~g}$. twice daily, this being increased by $0.1 \mathrm{~g}$. a day at weekly or fortnightly interva's until the necessary amount was being taken.

The number of attacks and the type were recorded at each interview, the frequency being later compared with that before methoin therapy, and improvement being calculated on a percentage basis thus:

$100-\left[\frac{\text { average number of attacks a month after treatment }}{\text { average number a month before treatment }} \times 100\right]$

Some difficulty was experienced in obtaining exact figures of both incidence and type of fit, as most of the patients suffering from major epilepsy had "warnings," or minor psychomotor phenomena, in addition to attacks of grand mal, and tended to neglect the smaller attacks in making their report. Similarly, patients with psychomotor epilepsy were not always conscious of their attacks, or could not be persuaded to keep a list of them other than in their heads. The results are therefore only approximate. 
TABLE I.-Results of Treatment

\begin{tabular}{|c|c|c|c|c|c|}
\hline $\begin{array}{l}\text { Case } \\
\text { No. }\end{array}$ & $\begin{array}{c}\text { Sex } \\
\text { and Age }\end{array}$ & $\begin{array}{l}\text { Type of } \\
\text { Epilepsy }\end{array}$ & $\begin{array}{l}\text { Duration of } \\
\text { Methoin } \\
\text { Treatment } \\
\text { (Months) }\end{array}$ & $\begin{array}{l}\text { Main- } \\
\text { tenance } \\
\text { Dosage } \\
\text { (G./Day) }\end{array}$ & $\begin{array}{c}\text { Result } \\
\text { (Percentage } \\
\text { Improve- } \\
\text { ment) }\end{array}$ \\
\hline $\begin{array}{r}1 \\
2 \\
3 \\
4 \\
5 \\
6 \\
7 \\
8 \\
9 \\
10 \\
11\end{array}$ & $\begin{array}{ll}\text { F } & 36 \\
F & 40 \\
F & 46 \\
F & 26 \\
F & 29 \\
M & 35 \\
\text { M } & 24 \\
\text { M } & 30 \\
\text { M } & 33 \\
\text { M } & 25 \\
\text { F } & 24\end{array}$ & $\begin{array}{c}\text { Major } \\
\text { ", } \\
\text { ", } \\
\text {," } \\
\text { ", } \\
\text { Major and }\end{array}$ & $\begin{array}{r}4 \\
7 \\
10 \\
6 \\
9 \\
2 \\
4 \\
4 \\
3 \\
5 \\
7\end{array}$ & $\begin{array}{l}0.9 \\
2 \cdot 1 \\
0.9 \\
0 \cdot 8 \\
0.9 \\
0.9 \\
1 \cdot 2 \\
0.9 \\
0 \cdot 3 \\
1 \cdot 2 \\
1 \cdot 2\end{array}$ & $\begin{array}{l}70 \\
\text { No change } \\
70 \\
100 \\
90 \\
\text { No change } \\
50 \\
50 \\
\text { No change } \\
60 \\
70+50\end{array}$ \\
\hline $\begin{array}{l}12 \\
13 \\
14\end{array}$ & $\begin{array}{ll}\text { F } & 48 \\
\text { M } 24 \\
\text { M } 24\end{array}$ & $\begin{array}{c}\text { psychomotor } \\
\text { " } \\
",\end{array}$ & $\begin{array}{l}8 \\
4 \\
2\end{array}$ & $\begin{array}{l}0.9 \\
0.9 \\
0.6\end{array}$ & $\begin{array}{l}50+\text { no change } \\
50+50 \\
\text { No change }+\end{array}$ \\
\hline 15 & M 19 & Major and focal & 5 & 0.9 & $100+50$ \\
\hline $\begin{array}{l}16 \\
17 \\
18 \\
19 \\
20 \\
21 \\
22 \\
23 \\
24\end{array}$ & $\begin{array}{ll}\text { F } & 40 \\
\text { F } & 27 \\
\text { F } & 41 \\
\text { F } & 10 \\
\text { F } & 23 \\
\text { F } & 22 \\
\text { M } & 31 \\
\text { M } & 21 \\
\text { M } & 26\end{array}$ & $\begin{array}{c}\text { Psychomotor } \\
\text { ", } \\
\text { ", } \\
\text { ", } \\
\text { ", }\end{array}$ & $\begin{array}{r}9 \\
9 \\
7 \\
3 \\
8 \\
9 \\
7 \\
10 \\
10\end{array}$ & $\begin{array}{l}0.6 \\
1.5 \\
0.9 \\
0.1 \\
0.6 \\
0.2 \\
0.9 \\
1.2 \\
0.9\end{array}$ & $\begin{array}{l}80 \\
\text { Slight } \\
\text { No change } \\
50 " ~ \\
100 \\
95 \\
60 \\
80\end{array}$ \\
\hline
\end{tabular}

\section{Results}

The results are shown in Table $I$. The degree of response to treatment has been divided into three (Table II) : much improved, indicating a $70 \%$ or more reduction in the frequency of attacks; improved, a $50-70 \%$ reduction; and no change if less than a $50 \%$ reduction.

TABLE II.-Degree of Response to Treatment

\begin{tabular}{|c|c|c|c|}
\hline & Much Improved & Improved & No Change \\
\hline $\begin{array}{l}\text { Major epilepsy } \\
\text { Psychomotor epilepsy .. }\end{array}$ & $\begin{array}{l}40 \% \\
31 \%\end{array}$ & $33 \%$ & $27 \%$ \\
\hline
\end{tabular}

It will be seen that best results were obtained with cases of grand mal, but, even so, they are less impressive than most of those reported in the literature. It is possible that selection is to some extent the cause of this: the cases were chosen from amongst a large number of epileptics, the bulk of whom had been attending hospital for some years. Thus there had been every opportunity for a trial of control by other means, and only those in obvious need of something better were given methoin.

A further point is that a certain number of patients, although their attacks were not fully controlled by methoin, stated that the fits were shorter in duration and milder in degree, or that a larger proportion of them did not progress beyond the aura stage.

\section{Illustrative Casès of Successful Treatment with Methoin}

Case 4.-A woman aged 26 developed major and minor epilepsy at the age of 10 . There was no significant past or family history, and no abnormal signs were observed on examination. She was an unstable person, much upset by her attacks, and had twice attempted suicide. With phenytoin, $0.5 \mathrm{~g}$. a day, and phenobarbitone, attacks were not controlled, and she became ataxic. With methoin, $0.8 \mathrm{~g}$. a day, she was free of attacks and considerably more equable in her behaviour.

Case 15.-A man aged 19, of epileptic stock, had his first attack at the age of 6 months, and by the time he was 11 years old frequent fits were occurring, usually preceded by paraesthesiae spreading up from the right leg to the right arm. There was a left parietal electroencephalographic focus, but air studies were normal. Before methoin treatment he was experiencing one to three major convulsions a week, with also frequent abortive sensory attacks. Pheno- barbitone, 4 gr. (0.26 g.), with phenytoin, 6 gr. (0.4 g.), daily, was ineffective and caused ataxia and severe acne. With methoin, $0.9 \mathrm{~g}$. a day, and dextro-amphetamire, $20 \mathrm{mg}$. a day, no further major attacks occurred, and focal sensory attacks were reduced by half. His behaviour, which for some years had been aggressive and sometimes violent, was not improved.

Case 21.-A woman aged 22 first developed epilepsy at the age of 10 , the attacks then consisting of sudden nausea, a bad smell at the back of her nose, and clouded consciousness. In later years she had had up to eight attacks a month of an epigastric aura followed by pallor, semipurposive hand movements, and sometines complete amnesia. At times attacks were followed by an indescribably bitter taste, but there were no convu'sions. No abnormal neurological signs were found, but there was a right anterior temporal electroencephalographic focus. Phenobarbitone, phenytoin, and troxidone were all ineffective, but only one attack occurred after methoin was given, and complete control has been maintained with $0.2 \mathrm{~g}$. a day. Her eosinophil count rose to $20 \%$ during the fourth month of treatment, but she was at that time suffering from a recurrence of hay-fever.

Case 24.-A man aged 26 was knocked out in a boxing match and had his first uncinate attack four weeks later. He was at that time drinking rather heavily. Since then he has continued to have attacks associated with a sweet taste, a sensation of déjà $v u$, and lip-smacking. He can continue wcrking or speaking during an attack, but usually checks his work afterwards to ensure that no mistake has been made. Phenytoin could not be increased beyond $0.6 \mathrm{~g}$. a day, but with methoin, $0.9 \mathrm{~g}$. a day, there is almost full control.

In Cases 21 and 24 methoin exerted its effect rapidly, and it has been noticeable also in other cases of the series that control was achieved early in those responding to treatment, while in those failing to respond large doses were little more effective than small.

\section{Cases Not Responding to Methoin}

Case 2.-A woman aged 40 developed epilepsy at the age of 19, the day after her first child was born. There was no family history of epilepsy or any neurological abnormality on examination. The attacks have not been adequately controlled by phenytoin or by methoin, $2.1 \mathrm{~g}$. a day, and the two drugs given together are not more effective.

Case 12.-A woman developed major epilepsy when aged 21. Now, at the age of 48 , she has up to 12 attacks a week and there is severe deterioration of personality. Complete investigation, including air studies, has shown no gross abnormality. Some of her present attacks are undoubtedly hysterical, though nearly all are associated with urinary incontinence. With methoin the grand mal attacks are possibly less frequent, but improvement is minimal.

Case 17.-This patient, a woman aged 27, weighed $13 \mathrm{lb}$. $(5.9 \mathrm{~kg}$.) at birth and was cyanosed during the first week of life. She developed normally, however, until the age of 8 , when a generalized convulsion occurred. Since then she has continued to suffer occasional grand mal attacks, but now has mainly psychomotor episodes, usually several each day. In them an epigastric aura is followed by a desire to run away, and then masticatory movements occur, she may rub her hands together, and is sometimes incontinent. She cannot speak during an attack. $X$-ray examination revealed a small calcified area in the left temporal lobe, and a slowwave electroencephalographic focus was present in the same site. Phenobarbitone, phenytoin, or methoin up to $1.5 \mathrm{~g}$. a day has not materially influenced the attack rate.

\section{Electroencephalographic Changes}

Little (1949) studied the effect of methoin on the electroencephalogram (E.E.G.) in 26 patients. In $62 \%$ an increase in fast activity occurred, and in $58 \%$ alpha 
activity was decreased. With continued dosage these effects became more pronounced, though there was no correlation between the E.E.G. changes and the therapeutic response. Fetterman and Victoroff (1949) found that in some of their cases the alpha activity became very regular, but they likewise observed no correlation between the E.E.G. pattern and the clinical state. Bercel and Ziskind (1950) stated that methoin led to an increase in fast activity in the E.E.G., and stressed its likeness to the barbiturates in this respect.

In the present series the E.E.G. changes were studied in 18 cases. In 15 there was an increase in fast $(20 \mathrm{c} / \mathrm{s})$ activity, sometimes to a marked extent; this did not seem to depend on the duration of treatment, though it disappeared rapidly in one case after withdrawal of methoin.

In eight cases a noticeable effect was the development of a uniform amplitude of all the frequencies. In some the E.E.G. became strikingly regular in appearance, particularly so when $6 \mathrm{c} / \mathrm{s}$ activity was prominent in the record. The finding is presumably related to the regular alpha activity reported by Fetterman, though in the present series this frequency was not affected more than others.

A decrease in slow-wave activity was seen in three cases, all of which also developed the increased regularity of pattern.

There was no correlation between the E.E.G. changes and the clinical state. This confirms previous reports, but is none the less surprising in view of the degree of change sometimes produced by methoin. The effect of barbiturates is to some extent comparable in that fast activity may occur during light sedation, but may-also persist during coma from barbiturate poisoning. Possibly methoin and the barbiturates have this effect in common because of their related chemical structure, as Bercel and Ziskind suggest, but it seems that the changes are not related to their- therapeutic effect.

\section{Methoin Toxicity}

In order to avert toxic reactions so far as possible methoin was started in small doses $(0.1 \mathrm{~g}$. twice daily) and gradually increased, whilst previously administered drugs were progressively withheld. Phenobarbitone, however, was usually stopped quickly owing to the soporific effect of methoin.

A strict system of control was used, regular blood counts and visits being enforced by giving only à limited supply of tablets. Patients were told to beware of sore throats, fever, skin rashes, malaise, and spontaneous bruising. They were instructed to report any such ill effects at once.

Mild Toxic Effects.-In $83 \%$ of the cases the patients complained of drowsiness, which in some continued throughout the period of treatment. In the majority small doses of dextro-amphetamine controlled the symptom fully. Other complaints were dizziness, indigestion, headache, constipation, frigidity, and gain in weight. The last-named occurred in two female patients to a quite marked degree. Gum hypertrophy and ataxiacommonly occurring with phenytoin-were not seen. One patient had had acne before treatment with methoin, and this became worse. A relative lymphocytosis, with or without eosinophilia, occurred in eight patients, and it may be of some significance that four of these gave a history of some form of allergic reaction in the past.
Acute Reactions.-An acute febrile reaction with morbilliform rash occurred in five patients $(21 \%)$--two occurred during the first week of treatment, two in the first month, and one in the fourth month. One of these had had an attack of urticaria in childhood, one had had infantile eczema and also developed a rash with phenytoin (but not with troxidone), and one developed a rash with troxidone; two did not give a history of previous sensitivity. Two patients not included in the series also developed rashes: one had had nettlerash once as a child, and the other had suffered from Raynaud's disease of the fingers.

It does seem, therefore, that patients with a history of previous sensitivity should be observed closely for a similar response to methoin, particularly during the early weeks of treatment. In all these patients methoin was temporarily stopped, but was gradually resumed without ill effect except in the case reported below.

\section{Severe Reactions}

There were three severe reactions, one terminating fatally

Case 19.- This patient suffered from frequent and severe psychomotor attacks and had failed to respond to troxidone or to phenytoin. With the latter drug a severe dermatitis, progressing almost to exfoliation, occurred, and was still evident when methoin was started in small doses. The rash resolved satisfactorily, but methoin could not be continued owing to a progressive degree of leucopenia.

Another patient (not included in the series) was taking $1.2 \mathrm{~g}$. of methoin a day in his fourth month of treatment when he complained of malaise and fatigue. The cervical lymph nodes were enlarged, and there was a petechial eruption over the shoulders. The red blood cell and platelet counts were normal, but there was a relative lymphocytosis of $58 \%$. After methoin had been stopped the rash subsided and the blood picture became normal.

\section{Case 16}

A woman aged 40 first had epilepsy at puberty with attacks resembling faints. After several years diurnal and nocturnal grand mal developed, but became infrequent during the last five years, when her main complaint was of distressing psychomotor attacks occurring in series. She had no significant past history, but there was a history of epilepsy in the family. Neurological examination revealed no abnormality.

On October 26, 1949, methoin, 0.2 g. daily, was started, but the patient stopped taking the tablets four days later because of a dazed feeling, this being followed in two days by malaise and a morbilliform rash. On November 9 the drug was resumed and was gradually increased to $0.6 \mathrm{~g}$. a day. This dosage controlled her attacks welland without ill effect except for drowsiness, which responded to dextroamphetamine.

On January 11, 1950, the patient was well but complained of a gain in weight. On March 11 she complained of soreness inside the mouth, but there was no apparent ulceration and the blood count was normal.

When seen on June 26 she was quite well, but on the night of June 30 she complained of ulceration of the mouth and difficulty in swallowing. The next day a blood count at another hospital revealed 700 white cells per c.mm., all being lymphocytes. She was admitted to that hospital, and examination showed haemorrhagic ulceration of the gums, bruising on the limbs, and a positive tourniquet test. Fresh blood transfusions, penicillin, and "aureomycin" were given, and the condition of her mouth improved. Later, however, severe menorrhagia and a high temperature developed, these continuing until her death on July 9. Serial blood examinations revealed a persisting complete agranulocytosis with scanty or absent blood platelets. 
At necropsy the bone marrow was found to be aplastic. There were generalized visceral petechiae and also a recent basal subarachnoid haemorrhage.

It is not known exactly when the blood picture in this case becare abnormal, as the illness began when the monthly blood count was due. Previous examination had not shown any abnormality, in particular no lymphocytosis or eosinophilia. When the patient was admitted, however, the granulocytopenia was already severe. She therefore developed a fatal aplastic anaemia eight months after starting methoin therapy. The symptoms were rapid in onset, though it is possible that signiffcant blood changes would have been recognized had more frequent examinations been carried out. There are, however, practical limits to this procedure.

Abbott and Schwab (1950) suggested that serious toxic effects were perhaps less likely to occur in patients developing a hypersensitive reaction early in the course of treatment, but such was not so in this case. It has also been maintained (though not specifically with methoin) that regular blood examinations are fruitless: that by the time changes are evident in the peripheral blood it is probably too late to attempt treatment. An alternative supposition is that blood dyscrasias are of sudden onset and therefore not subject to discovery by regular counts. Abbott and Schwab discounted this, however, and the safest course must remain that of examining the blood as regularly as possible during treatment.

\section{Discussion}

As has happened with other new preparations in recent years, methoin proves to be a valuable but sometimes toxic drug. This study confirms its usefulness in major and also in psychomotor epilepsy, and shows that dramatic results may sometimes be obtained. It is, however, a drug of definite toxicity, and its use may be fatal.

Clearly, methoin should be used only when every attempt to obtain control by other means has failed. As beneficial effects usually appear quickly, it is better not to persist with it in patients who are resistant; on the other hand, a short therapeutic trial may be made with little danger.

If methoin is used certain precautions must be routine : (1) Instruction of the patient and relatives on its possible dangers, with the warning that they must report any suspicious symptoms at once. The patient's own doctor ought also to be notified that the drug is in use. (2) It should not be used in conjunction with other drugs likely to cause similar reactions. It should not be used with troxidone, though a number of resistant cases seem to demand this very combination. (3) The patient must be seen and blood examinations carried out regularly throughout the period of treatment.

\section{Summary}

The results of methoin treatment in 24 cases of major and psychomotor epilepsy are described. A reduction of $70 \%$ or more in fits occurred in $40 \%$ of major epilepsy cases, and in $31 \%$ of patients with psychomotor epilepsy.

Details of E.E.G. changes due to the drug are given.

Toxic effects, including a fatal aplastic anaemia in one case, are described.

The value and limitations of methoin are discussed.

It is a pleasure to record the help of Dr. Denis Hill, at whose suggestion the trial was undertaken. I am also indebted to Dr. T. V. Mendelsohn for his detailed report on the fatal case, and to the Department of Clinical Pathology at the Maudsley Hospital for carrying out the large number of routine blood tests.

\section{REFERENCES}

Abbott, J. A., and Schwab, R. S. (1950). New Engl. J. Med., 242,943 .

Aird, R. B. (1948). Calif. Med., 68, 141.

Bercel, N. A., and Ziskind, E.'(1950). Electroenceph. \& clin. Neurophysiol., 2, 222.

Boller, W. (1943). Schweiz. med. Wschr., 73, 699.

Fetterman, J. L., Friedman, M. D., Weil, A. A., and Victoroff, V. M. (1947). Ohio St. med. J., 43, 1251 .

and Victoroff, V. M. (1949). Dis. nerv. Syst., 10, 355.

- and Weil, A. A. (1947). Med. clin. N. Amer., 31, 1273.

$\overline{\text { Gibbs, F. A. (1947). Ann. intern. Med., 27, } 548 .}$

Harris, T. H., and Otto, J. L. (1947). Tex. St. J. Med., 43, 328.

Kozol, H. L.' (1946). Amer. J. Psychiat., 103, 154

- (1947). Ass. Res. nerv. ment. Dis. Proc., 26, 404

(1950). Arch Neurol. Psychiat. Chicago 63, 235.

Lennox, W. G. (1946). Amer. J. Psychiat., 103, 159. Levy, R. W., Simons, D. J., and Aronson, S. (1950). New. Engl.

Little, S. C."(1949). Electroenceph. \& clin. Neurophysiol., 1, 325.

Loscalzo, A. E. (1945). J. nerv. ment. Dis., 101, 537.

- (1946). Amer. J. Psychiat. 103, 157.

- (1947). J. Amer. med. Ass., 135, 496

(1948). Ibid., 138, 1114

Ruskin, D. B. (1948). Ibid., 137, 1031.

\section{TUBERCULOSIS IN KENYA}

BY

W. S. HAYNES, M.A., M.D.

Medical Officer, Colonial Medical Service, Kenya

\section{Details of the Survey}

A tuberculosis survey of Kenya Colony was made between February, 1948, and February, 1949. In default of mass miniature radiography, the method of the survey was limited to tuberculin-testing, physical examination, and the examination of sputa. It was possible to get only a single specimen of sputum from each suspect, the likeliest-looking part of which was smeared on a slide, dried, and subsequently examined at the Government Laboratory in Nairobi by the ZiehlNeelsen method. The usual methods of physical examination were employed, but care was taken to exclude all cases except those with definite and persistent signs. Unequivocal signs of cavitation were taken as a proof of tuberculosis; bronchial breath sounds and posttussic crepitations were, unless there was evidence of recent acute infection, classified as suspicious of the disease.

Although limited in method, the survey was of considerable extent. Africans were examined at 34 different places, chosen as giving a fair sample of the more populous parts of the colony. In all, 49,812 intradermal injections of $0.1 \mathrm{ml}$. of 1 in 1,000 old tuberculin were given, and a reading was obtained 48 hours later in 42,492 instances. An indurated area more than $5 \mathrm{~mm}$. in diameter, palpable 48 hours after the injection, was taken as constituting a positive reaction. A total of 2,889 physical examinations were made, and 1,298 specimens of sputum were examined for tubercle bacilli.

\section{Control Series}

Some attempt was made to rule out non-specific allergy to old tuberculin, which might be supposed to occur in the African, prone as he is to helminth and protozoal infections. Ninety-eight hospital patients were given an intradermal injection of $0.1 \mathrm{ml}$. of $5 \%$ 